\title{
KRITERIA SELEKSI MASUK FAKULTAS KEDOKTERAN SEBAGAI PREDIKTOR PRESTASI AKADEMIK
}

\author{
Dedeh Supantini, Lusiana Darsono, Winsa Husin \\ Fakultas Kedokteran Universitas Kristen Maranatha Bandung \\ Korespondensi: Dedeh Supantini, Bagian IImu Penyakit Saraf \\ Fakultas Kedokteran Universitas Kristen Maranatha Bandung.
}

\begin{abstract}
Background: Selection of students into medical school should have two distinct purposes: to enroll students that most likely to succeed in their academic and clinical year, and subsequently become competent and professional medical practitioner. Numbers of applicants and numbers of students accepted in Faculty of Medicine of Maranatha Christian University (MCU) was tend to increase each year. The selection of medical students was based on General Admission Test (GAT) prepared by admission committees of MCU. To improve the selection procedure, since 2009, the Faculty developed Medical Faculty Admission Test (MFAT) as additional selection tool to assess cognitive attributes in basic biomedical sciences.

Objectives: The objective of this study was to evaluate how well the selection criteria predict academic performance, and to identify if there were any aspects of prior academic history and student's characteristic that correlate with subsequent students performance during medical program.

Methods: We studied students cohort of the 2009. Selection criteria were GAT and MFAT. Prior academic performance explained by student's score on National High School Examination (NHSE) and student's score on biology. Academic performance was defined as cumulative first year Grade Point Average (GPA). Correlation between GPA and selection criteria or student's characteristic was calculated using Pearson's correlation coefficient. Multiple regressions was performed for each outcome variable with all variables included. Statistical significance was set at $\mathrm{p}<0,05$

Results and Discussion: There were 167 students included in this study. Bivariate correlation analysis with Pearson's correlation showed that MFAT $(=0,354, \mathrm{p}<0,01)$ and GAT $(\mathrm{r}=0,301, \mathrm{p}<0,01)$ were correlated with student's academic performance. The results of multivariate analysis with multiple regression showed that MFAT and GAT are predictors of first year academic performance defined by GPA ( $\mathrm{R}$ multiple $=0,404, \mathrm{p}<0,001)$.
\end{abstract}

Conclusion: Medical Faculty of MCU selection criteria ere correlated with academic performance.

Key Words: Selection Criteria, academic, achievement, grade point average.

\begin{abstract}
Abstrak
Latar belakang: Seleksi calon mahasiswa Fakultas Kedokteran (FK) harus bertujuan untuk menyaring mahasiswa yang diprediksi (1) akan berhasil dalam pendidikan dan (2) menjadi dokter yang kompeten serta profesional. Jumlah pendaftar dan jumlah mahasiswa yang diterima di FK Universitas Kristen Maranatha (UKM) meningkat setiap tahunnya. Seleksi masuk FK UKM adalah berdasarkan Tes Seleksi Umum (TPA). Untuk meningkatkan kualitas mahasiswa, sejak tahun 2009, FK UKM mengembangkan tes seleksi khusus masuk FK (TSFK) sebagai instrumen tambahan untuk menguji aspek kognitif di bidang Ilmu Biomedik Dasar.

Tujuan: Tujuan penelitian ini adalah mengevaluasi seberapa jauh kedua kriteria seleksi tersebut (TPA dan TSFK) dapat memprediksi performa akademik mahasiswa, serta mengidentifikasi apakah karakteristik mahasiswa dan prestasi akademik sebelumnya berkorelasi dengan performa mahasiswa selama pendidikan di FK.

Metoda: Subjek penelitian adalah kohor mahasiswa angkatan 2009. Kriteria seleksi yang dievaluasi adalah TPA dan TSFK. Riwayat prestasi akademik dievaluasi berdasarkan nilai Ujian Nasional (UN) Sekolah Menengah Umum (SMU) serta nilai
\end{abstract}

Korespondensi: Nindya Aryanty, Jl. Rajawali I No. 3, Jambi, Indonesia, 36138, Telp +6285266937383,

email: nindya_aryanty@yahoo.co.id 
Biologi dalam ijazah SMU. Performa akademik di FK diukur dengan Indeks Prestasi Kumulatif (IPK) tahun pertama. Korelasi antara IPK dengan karakteristik mahasiswa maupun kriteria seleksi dihitung berdasarkan koefisien korelasi Pearson, kemudian dilakukan regresi multipel. Kemaknaan statistik ditetapkan pada $\mathrm{p}<0,05$.

Hasil: Subjek penelitian terdiri dari 167 mahasiswa. Analisis bivariat dengan uji korelasi Pearson menunjukkan bahwa TSFK $(\mathrm{r}=0.354, \mathrm{p}<0.01)$ dan TPA $(\mathrm{r}=0.301, \mathrm{p}<0.01)$ berkorelasi dengan performa akademik. Hasil uji regresi multipel menunjukkan bahwa TSFK dan TPA merupakan prediktor prestasi akademik tahun pertama yang diukur dengan IPK $(\mathrm{R}$ multipel $=0.404$, $\mathrm{p}<0.001)$.

Kesimpulan: Kriteria seleksi masuk FK UKM berkorelasi dengan prestasi akademik.

Kata Kunci: Kriteria seleksi - prestasi akademik - IPK

\section{PENDAHULUAN}

Seleksi masuk ke Fakultas Kedokteran (FK) memiliki kriteria khusus. Kriteria seleksi ini harus bertujuan untuk menyeleksi mahasiswa yang diasumsikan akan berhasil menempuh masa studi mereka di Fakultas Kedokteran dan kelak dapat menjadi seorang dokter yang profesional. $^{1}$

Penelitian terdahulu di negara-negara maju menunjukkan bahwa prestasi akademik sebelum masuk Fakultas Kedokteran dan performa dalam tes seleksi masuk khusus merupakan prediktor prestasi akademik di Fakultas Kedokteran, sedangkan wawancara khusus serta tes psikometrik tertentu kurang bermakna sebagai alat penyaring., ${ }^{2,3}$

Fakultas Kedokteran Universitas Kristen Maranatha (FK UKM) berdiri sejak tahun 1965. Dari tahun ke tahun terdapat peningkatan jumlah calon mahasiswa FK UKM. Jumlah mahasiswa juga meningkat secara signifikan untuk memenuhi kebutuhan masyarakat akan ketersediaan dokter sebagai pelayan kesehatan. Selama beberapa dekade, tidak terdapat tes seleksi khusus untuk penerimaan mahasiswa FK UKM. Penerimaan mahasiswa FK UKM ditetapkan berdasarkan peringkat calon mahasiswa dalam Tes Potensi Akademik (TPA). Sebagai salah satu upaya untuk meningkatkan mutu pendidikan, sejak tahun 2009 FK UKM menetapkan kriteria tambahan bagi calon mahasiswa yang akan diterima di FK UKM, yaitu tes seleksi khusus berupa ujian tulis materi Ilmu Pengetahuan Alam yang berkaitan dengan Medical Science (Tes Seleksi Khusus FK, TSFK).
Belum diketahui sejauh mana kriteria seleksi masuk yang di tetapkan tersebut dapat menyaring calon mahasiswa yang benar-benar mempunyai kualifikasi untuk menempuh studi di FK. Karena itu kami mengadakan penelitian yang bertujuan untuk mengetahui apakah kriteria seleksi masuk calon mahasiswa FK UKM merupakan prediktor prestasi akademik selama studi di FK.

\section{TUIUAN}

Tujuan penelitian ini adalah mengetahui apakah kriteria seleksi masuk bagi calon mahasiswa FK UKM dapat memprediksi prestasi akademik dalam studi mereka dan mengidentifikasi karakteristik lain dari mahasiswa yang berkorelasi dengan keberhasilan akademik.

\section{METODE}

\section{Konteks Penelitian}

Seleksi masuk Fakultas Kedokteran Universitas Kristen Maranatha (FK UKM) biasanya dilakukan berdasarkan penelusuran minat dan kemampuan siswa (PMDK) dan tes seleksi penerimaan mahasiswa baru (SPMB). Panitia Seleksi Penerimaan Mahasiswa Baru (SPMB) menjaring siswa-siswa berprestasi baik dari beberapa sekolah unggulan baik di kota Bandung maupun kota-kota lain melalui PMDK. Penilaian dilakukan berdasarkan nilai raport SMU dan kualitas SMU yang bersangkutan. Seleksi melalui SPMB dilakukan berdasarkan skor TPA. Hasil TPA yang diurutkan berdasarkan peringkatnya dilaporkan oleh panitia SPMB kepada rektorat. Kemudian pihak rektorat bersama-sama dengan dekan Fakultas Kedokteran dalam suatu rapat judisium 
menentukan nilai batas lulus dan memutuskan calon mahasiswa yang diterima.

Dalam upaya untuk meningkatkan kualitas pendidikan, FKUKM mengusulkan kriteria tambahan dalam seleksi mahasiswa baru, yaitu berupa Tes Seleksi khusus FK (TSFK). TSFK dikembangkan oleh tim yang ditunjuk dengan surat keputusan dekan, yang terdiri dari dosendosen biologi, kimia dan biokimia. Soal dibuat berdasarkan materi mata pelajaran biologi dan kimia SMU kurikulum 2004. Diasumsikan bahwa tes ini mengevaluasi pengetahuan calon mahasiswa dalam basic science yang menjadai prior knowledge yang penting untuk menempuh studi di FK. Soal yang telah disusun oleh narasumber di-review oleh tim sebelum dikirimkan ke panita SPMB. Tes Seleksi khusus ini mulai dijalankan sejak tahun akademik 2009. Pada periode tersebut, jumlah pendaftar adalah sebesar 1113 orang dan diterima sebanyak 271 orang.

\section{Subjek dan Metode}

Pada akhir tahun akademik 2009 - 2010 dilakukan penelitian historical kohort terhadap mahasiswa angkatan 2009. Sampel yang dimasukkan ke dalam penelitian adalah mahasiswa FK UKM angkatan 2009. Kriteria inklusi adalah sebagai berikut :

1) Mahasiswa yang tercatat aktif mengikuti pembelajaran selama 2 (dua) semester

2) IPK nya dapat dihitung
Data yang dikumpulkan meliputi variabel bebas berupa karakteristik demografi (usia, jenis kelamin, asal SMU di pulau Jawa atau luar Jawa), NEM dan nilai IPA di SMU, skor TPA dan Skor TSFK. Sedangkan variabel independen berupa IPK rata-rata tahun pertama.

Korelasi antara luaran prestasi akademik (IPK) dan kriteria seleksi (TPA, TSFK) serta variabel lainnya dianalisis secara statistik dengan menggunakan koefisien korelasi pearson. Untuk memprediksi nilai variabel dependen (IPK) jika variabel independen dimanipulasi, maka dilakukan analisis regresi multipel. Kemaknaan statistik ditetapkan pada $p<0,05$. Analisis akan dilakukan dengan menggunakan piranti lunak SPSS.

Penelitian telah mendapat ijin dekan FK UKM. Data berupa nilai TPA dan TSFK diperoleh dari panitia SPMB. Nilai NEM dan IPK diperoleh dari ketua program studi pendidikan dokter (PSPD).

\section{HASIL DAN PEMBAHASAN}

Jumlah mahasiswa yang diterima di FK UKM pada tahun akademik 2009-2010 adalah 271 orang. Di antara jumlah tersebut, 190 orang melakukan daftar ulang, namun 19 diantaranya membatalkan diri karena diterima di Perguruan Tinggi Negeri. Jumlah mahasiswa angkatan 2009 adalah 171 orang, terdiri dari 66 $(38,6 \%)$ pria dan 105 (61,4\%) wanita. Dari jumlah tersebut, hanya 167 yang memenuhi kriteria inklusi dan menjadi subjek penelitian. Beberapa karakteristik subjek dapat dilihat pada Tabel 1.

Tabel 1. Karakteristik subjek

\begin{tabular}{|c|c|c|}
\hline & & Jumlah (\%) \\
\hline Usia (tahun) & & \\
\hline Mean $\pm \mathrm{SD}$ & $18.7 \pm 1.1$ & \\
\hline Range & $16-25$ & \\
\hline Jenis kelamin & & \\
\hline a. Wanita & & $103(61.7 \%)$ \\
\hline b. Pria & & $64 \quad(38.3 \%)$ \\
\hline Asal SMU & & \\
\hline a. Pulau Jawa & & $140(8.3 .8 \%)$ \\
\hline b. Luar Jawa & & $27 \quad(16.2 \%)$ \\
\hline Nilai Ebtanas Murı & & \\
\hline Mean \pm SD & $48.0 \pm 7.3$ & \\
\hline Range & $29.4-82.4$ & \\
\hline
\end{tabular}




\begin{tabular}{|c|c|c|}
\hline \multicolumn{3}{|c|}{ Nilai SMU (mean \pm SD) } \\
\hline Bahasa Inggris & $8.6 \pm 0.8(5.0-10.0)$ & \\
\hline Biologi & $7.7 \pm 1.0(4.8-10.0)$ & \\
\hline Kimia & $8.7 \pm 1.0(4.0-10.0)$ & \\
\hline Matematika & $7.9 \pm 1.4(3.0-10.0)$ & \\
\hline \multicolumn{3}{|l|}{ Skor TPA } \\
\hline Mean \pm SD & $73.4 \pm 33.2$ & \\
\hline Range & $66-100$ & \\
\hline \multicolumn{3}{|l|}{ Skor TSFK } \\
\hline Mean $\pm S D$ & $44.3 \pm 22.5$ & \\
\hline Range & $15-82$ & \\
\hline \multicolumn{3}{|c|}{ Kategori jalur penerimaan } \\
\hline PMDK & & $26(16 \%)$ \\
\hline SPMB & & $141(84 \%)$ \\
\hline \multicolumn{3}{|l|}{ IPK scmester I } \\
\hline Mean \pm SD & $3.20 \pm 0.54$ & \\
\hline Range & $1.50-4.00$ & \\
\hline \multicolumn{3}{|l|}{ IPK semester II } \\
\hline Mean \pm SD & $3.07 \pm 0.56$ & \\
\hline Range & $0.88-3.94$ & \\
\hline \multicolumn{3}{|l|}{ IPK semester II } \\
\hline Mean \pm SD & $3.13 \pm 0.54$ & \\
\hline Range & $1.19-3.97$ & \\
\hline
\end{tabular}

Tabel 2. Pencapaian IPK tahun pertama pada kelompok PMDK dan non-PMDK serta menurut jenis kelamin

\begin{tabular}{|c|c|c|c|c|c|}
\hline \multirow{2}{*}{ Variabel } & \multicolumn{3}{|c|}{ IPK tahun pertama } & \multirow{2}{*}{$t$ test } & \multirow{2}{*}{$\mathbf{p}$} \\
\hline & $\overline{\mathbf{n}}$ & mean & $\overline{\mathrm{SD}}$ & & \\
\hline $\begin{array}{l}\text { 1. Jalur seleksi masuk } \\
\text { a. PMDK } \\
\text { b. Non-PMDK }\end{array}$ & $\begin{array}{l}26 \\
141\end{array}$ & $\begin{array}{l}3,30 \\
3,11\end{array}$ & $\begin{array}{l}0,54 \\
0,53\end{array}$ & 1,622 & 0,107 \\
\hline $\begin{array}{l}\text { 2. Jenis kelamin } \\
\text { a. Laki-laki } \\
\text { b. Perempuan }\end{array}$ & $\begin{array}{l}64 \\
103\end{array}$ & $\begin{array}{l}3,04 \\
3,20\end{array}$ & $\begin{array}{l}0,60 \\
0,50\end{array}$ & $-1,818$ & 0,071 \\
\hline
\end{tabular}

Dari Tabel 2 tampak bahwa IPK tahun pertama terdistribusi secara merata pada kelompok PMDK maupun non-PMDK, juga pada kedua kelompok jenis kelamin. 
Tabel 3. Kelompok PMDK dan non-PMDK

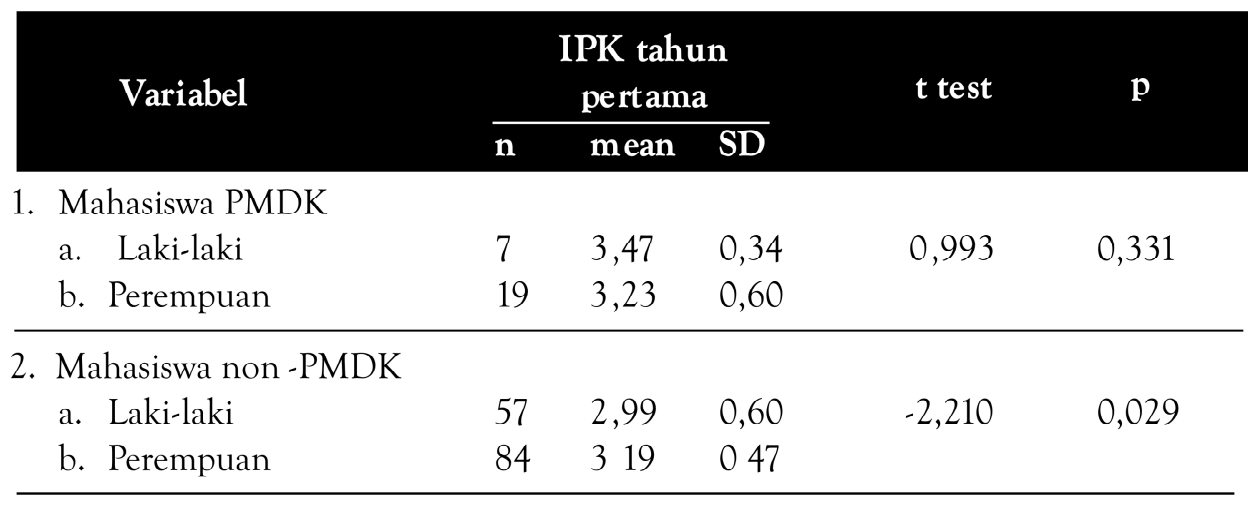

Pada Tabel 3 tampak bahwa pada kelompok PMDK, IPK terdistribusi merata pada mahasiswa laki-laki maupun perempuan, namun pada kelompok nonPMDK tampaknya mahasiswa perempuan mempunyai IPK lebih baik dibanding laki-laki $(\mathrm{p}<0,05)$.

Korelasi antara variabel bebas dengan luaran IPK tahun pertama dihitung dengan koefisien korelasi pearson (Tabel 4). Ternyata pada semua mahasiswa, nilai bahasa inggris selama SMU berkorelasi lemah dengan IPK. Tampak korelasi kuat antara nilai bahasa inggris dengan IPK pada kelompok PMDK (r 0,650, p<0,01). Pada kelompok mahasiswa yang masuk melalui test seleksi masuk, baik TPA maupun TSFK berkorelasi sedang dengan IPK, dan ternyata TSFK mempunyai korelasi lebih baik dengan IPK (r 0,354, p<0,01) dibandingkan dengan TPA (r 0,301, $\mathrm{p}<0,01)$.

Tabel 4. Korelasi antara variabel bebas dengan IPK tahun pertama

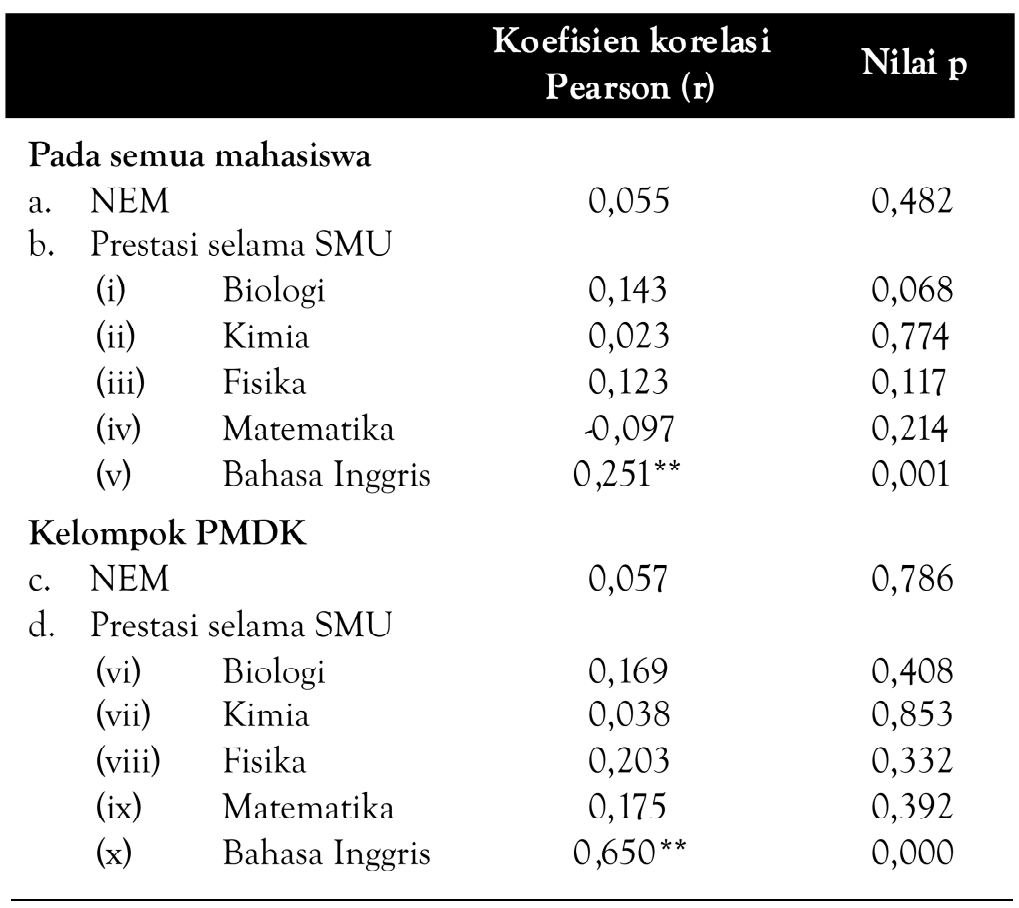




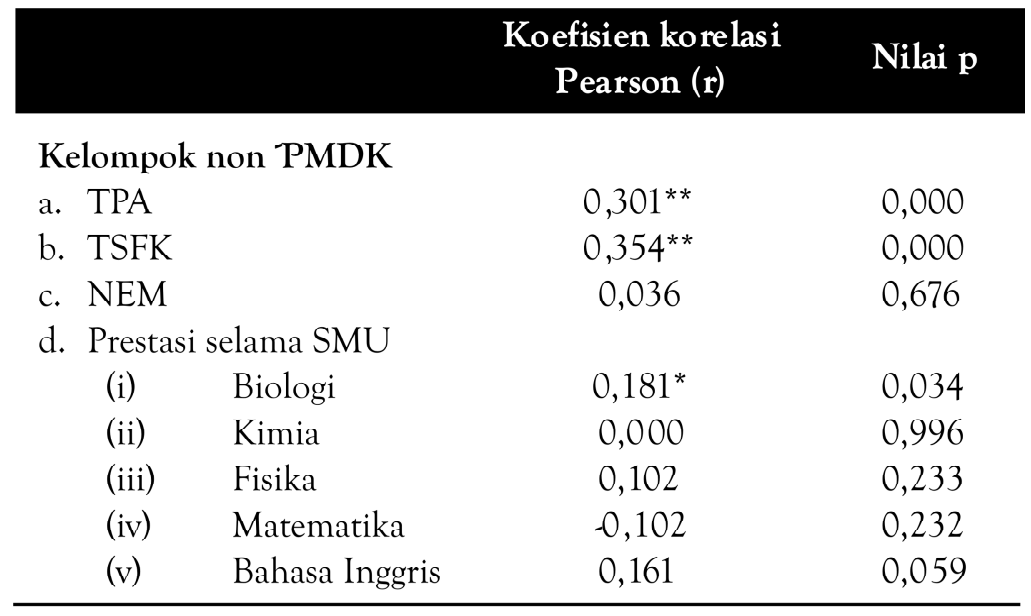

**. Correlation is significant at the 0.01 level (2-tailed)

*. Correlation is significant at the 0.05 level (2-tailed)

Untuk memprediksi nilai IPK yang dihasilkan oleh pengaruh dari satu atau lebih variabel bebas, maka dilakukan analisis multivariate dengan regresi ganda. Variabel bebas yang masuk model regresi adalah NEM, TPA, TSFK dan nilai Biologi SMU. Hasil akhir analisis multivariate ini (Tabel 5) memperlihatkan bahwa prediktor dari IPK adalah TPA dan TSFK, dengan $\mathrm{R}$ ganda $=0,404, p<0,001)$.

Tabel 5. Model akhir saling keterkaitan antara TPA dan TSFK dengan IPK tahun pertama

\begin{tabular}{lccc} 
& Koefisien B & SE ( $\boldsymbol{\beta})$ & Nilai p \\
TPA & 0,016 & 0,006 & 0,008 \\
TSFK & 0,015 & 0,004 & 0,001 \\
Constant & 0,931 & 0,508 & 0,069 \\
\hline
\end{tabular}

Keterangan :

NEM dan Biologi dikeluarkan dari model karena mempunyai nilai $p>0,05$ (untuk NEM nilai $p=0,923$, untuk Biologi nilai $\mathrm{p}=0,147)$

Dari hasil di atas, persamaan regresi yang diperoleh adalah :

IPK tahun pertama $=0,931+0,016 \mathrm{TPA}+0,015$ TSFK ( $\mathrm{R}$ multipel $=0,404, \mathrm{p}<0,001)$

Dari model akhir ini tampak bahwa TPA sedikit lebih besar pengaruhnya dibanding TSFK dalam menentukan IPK tahun pertama.
Penelitian ini memiliki beberapa keterbatasan yang harus dipertimbangkan dalam interpretasi temuan yang dihasilkan. Penelitian kami terbatas pada angkatan 2009 karena TSFK baru dilaksanakan sejak tahun 2009, sehingga IPK yang dijadikan sebagai tolak ukur evaluasi hanya rata-rata IPK tahun pertama. Hal ini memungkinkan terjadinya bias mengingat adanya kemungkinan bahwa dalam tahun pertama mahasiswa masih dalam tahap adaptasi terhadap situasi dan metode pembelajaran di Fakultas Kedokteran UKM yang menggunakan kurikulum berbasis kompetensi dengan model student centered.

Walaupun beberapa penelitian terdahulu menemukan korelasi antara prestasi akademik di SMU dengan prestasi mahasiswa di FK, pada penelitian kami hanya tampak bahwa IPK rata-rata dari kelompok PMDK $(3,30 \pm 0,54)$ lebih baik daripada kelompok non$\operatorname{PMDK}(3,11 \pm 0,53)$, namun secara statistik perbedaan tersebut ternyata tidak signifikan $(\mathrm{p}=0,107)$. Pada seluruh mahasiswa, riwayat prestasi selama SMU yang berkorelasi dengan IPK ternyata hanya dalam nilai pelajaran bahasa inggris $(r=0,251, p<0,01)$.

Hasil penelitian memperlihatkan bahwa baik skor TPA maupun TSFK mempunyai korelasi cukup dengan IPK mahasiswa, di mana skor TSFK $(r=0,354, p<0,01)$ berkorelasi lebih baik dengan IPK dibandingkan skor TPA (r 0,301, p < 0,01). 
Hasil akhir model regresi multipel dalam penelitian ini menunjukkan bahwa TPA dan TSFK merupakan prediktor IPK tahun pertama. Diperoleh koefisien determinasi untuk TPA dan TSFK adalah $R$ square $0,163(\mathrm{p}<0,01)$, maka diasumsikan bahwa TPA dan TSFK hanya dapat menjelaskan $16,3 \%$ variasi IPK tahun pertama. Namun angka ini cukup baik bila dibandingkan dengan temuan Wilkinson et al yang memperoleh angka prediktif sebesar 20\% dari kriteria seleksi yang mereka tetapkan, di mana sebenarnya angka tersebut berkisar antara 10-30\% tergantung dari tahun akademiknya.

Para pakar pendidikan kedokteran menyatakan bahwa kriteria seleksi masuk FK harus spesifik dan meliputi beberapa ranah, termasuk ranah non-kognitif termasuk motivasi calon mahasiswa, minat, kemampuan belajar mandiri, kemampuan komunikasi dan beberapa karakteristik lain. Hal ini dibeberapa pusat pendidikan dievaluasi dengan menggunakan format wawancara terstruktur. Beberapa peneliti menemukan korelasi positif antara hasil wawancara terstruktur dengan prestasi akademik. Bahkan Wilkinson et al. menemukan bahwa hasil wawancara terstruktur berkorelasi lebih kuat dibandingkan dengan tes seleksi khusus Fakultas Kedokteran (GAMSAT = Graduate Australian Medical School Admissions Test). Berdasarkan hal ini dan meng- ingat bahwa TPA dan TSFK hanya dapat menjelaskan 16,3\% variasi IPK di FK UKM, maka tim SPMB dan FK UKM harus mempertimbangkan kriteria seleksi tambahan berupa evaluasi aspek non-kognitif yang penting dalam pencapaian prestasi akademik di FK.

\section{KESIMPULAN}

Dari penelitian ini dapat diambil kesimpulan bahwa kriteria seleksi yang kami tetapkan merupakan prediktor keberhasilan akademik di FK. Skor TSFK berkorelasi lebih baik dengan IPK dibandingkan skor TPA.

\section{DAFTAR PUSTAKA}

1. Shokar GS, Shokar NK, Romero CM, Bulik RJ. Selfdirected learning: looking at outcomes with medical students. Family Medicine. 2002; 34(3):197-200.

2. Frisby AJ. Self-directed learning readiness in medical students at the Ohio State University (dissertation). Thomas Jefferson University; 1991. Dikutip dari: AISR Staff papers and presentations.

3. Dent JA, Harden RM. A practical guide for medical teachers. $2^{\text {nd }}$ Ed. Elsevier Churchill Livingstone; 2005.

4. Harden RM, Sowden S, Dunn WR. Educational strategies in curriculum development: the SPICES model. Medical Education. 1984; 18: 284-97.

5. Albanese MA, Mitchell S. Problem-based learning: A review of literature on its outcomes and implementation issues. Academic Medicine. 1993; 68: 52-81. 